\title{
THE BLOOD PRESSURE IN PARAPLEGIA I
}

\author{
By H. L. Frankel, L. S. Michaelis, D. R. Golding and Valerie Beral \\ National Spinal Injuries Centre, Stoke Mandeville Hospital
}

\section{INTRODUCTION}

THE resting blood pressure (B.P.) in tetraplegic patients is known to be low. Some paraplegics (including tetraplegics) have pathologically high B.P.; this hypertension often develops many years after the onset of the paraplegia and may be associated with renal complications. The incidence of hypertensive changes and renal complications is high in post-mortem studies of paraplegia (Tribe, 1963; Talbot, I966; Tribe \& Silver, I969).

There is no general agreement about the limits of normal B.P. in the nonparaplegic population and in order to determine the prevalence of hypertension in living paraplegics a population study was needed. However it was first necessary to determine the range of physiological B.P. for any particular level of paraplegia. The object of this article is to establish these physiological levels.

\section{MATERIAL AND METHOD}

The material at present available from the records of the National Spinal Injuries Centre, Stoke Mandeville Hospital was used. Past records were extracted and recorded on punch cards (I.B.M. 80-column punch cards connected to an I.B.M. I I30 computer). Information on each patient was covered in 480 columns for the patient's first admission and 68 columns for each check-up. By means of the I.B.M. I I30 system, we will eventually be able to interrelate all the facts contained in the system (figs. I and 2).

In previous investigations of this type, patients were divided into groups, the usual grouping at Stoke Mandeville Hospital is:

Cervical

TI-T5

T6-Ti2

Below Ti2

In order to establish whether these were correct or meaningful, it was decided to analyse the B.P.s of patients at each available spinal cord level. This was carried out at the patients' first check-up following their initial discharge from hospital. (This time was chosen to eliminate unreliable early readings and the effects of late complications.) Only patients who had a permanently complete spinal cord lesion of traumatic origin were included.

The B.P. was measured by the doctor performing the check-up, and readings were taken by many different doctors, all of whom were experienced in the field of spinal injuries. Some recorded the B.P. to the nearest $2 \mathrm{~mm}$. $\mathrm{Hg}$ and others to the nearest $5 \mathrm{~mm}$. Hg. The patients were examined while either supine on a bed, lying flat, semi-sitting or sitting. In general, the doctors taking the B.P. were sufficiently experienced to detect or suspect autonomic dysreflexia and, when this was a temporary phenomenon, the subsequent resting B.P. was recorded. 
Shown in Figure 3 are the number of patients with lesions complete below any spinal cord level. Only a small number of females are shown but there is a similar distribution of lesions in both sexes. There are peaks at $\mathrm{C}_{5}-\mathrm{C}_{7}, \mathrm{~T}_{10}-\mathrm{T}_{12}$ and smaller peaks at $\mathrm{T}_{5}-\mathrm{T}_{7}$.
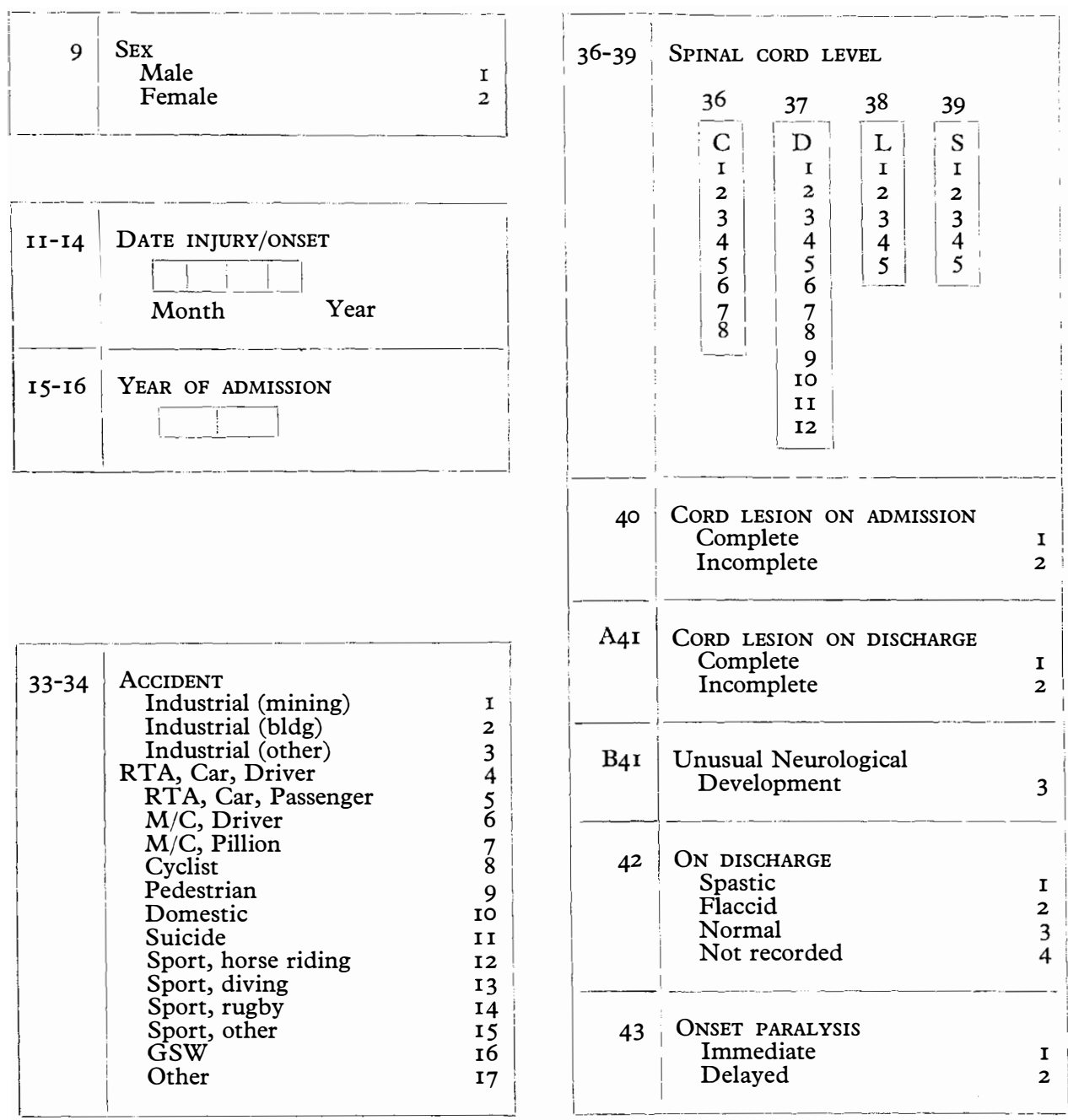

\begin{tabular}{|c|c|c|}
\hline $33-34$ & $\begin{array}{l}\text { ACCIDENT } \\
\text { Industrial (mining) } \\
\text { Industrial (bldg) } \\
\text { Industrial (other) } \\
\text { RTA, Car, Driver } \\
\text { RTA, Car, Passenger } \\
\text { M/C, Driver } \\
\text { M/C, Pillion } \\
\text { Cyclist } \\
\text { Pedestrian } \\
\text { Domestic } \\
\text { Suicide } \\
\text { Sport, horse riding } \\
\text { Sport, diving } \\
\text { Sport, rugby } \\
\text { Sport, other } \\
\text { GSW } \\
\text { Other }\end{array}$ & $\begin{array}{r}1 \\
2 \\
3 \\
4 \\
5 \\
6 \\
7 \\
8 \\
9 \\
10 \\
11 \\
12 \\
13 \\
14 \\
15 \\
16 \\
17\end{array}$ \\
\hline
\end{tabular}

FIG. I

Portions of first punch card sheet showing information relevant to this study.

\section{RESULTS}

The number of females in each level was small, therefore only the male results were analysed.

Figure 4 shows the systolic B.P. plotted against the level of the lesion. The results of all the cervical lesions were pooled because the numbers at every level, except C6, were rather small (when these small numbers were plotted there was no 


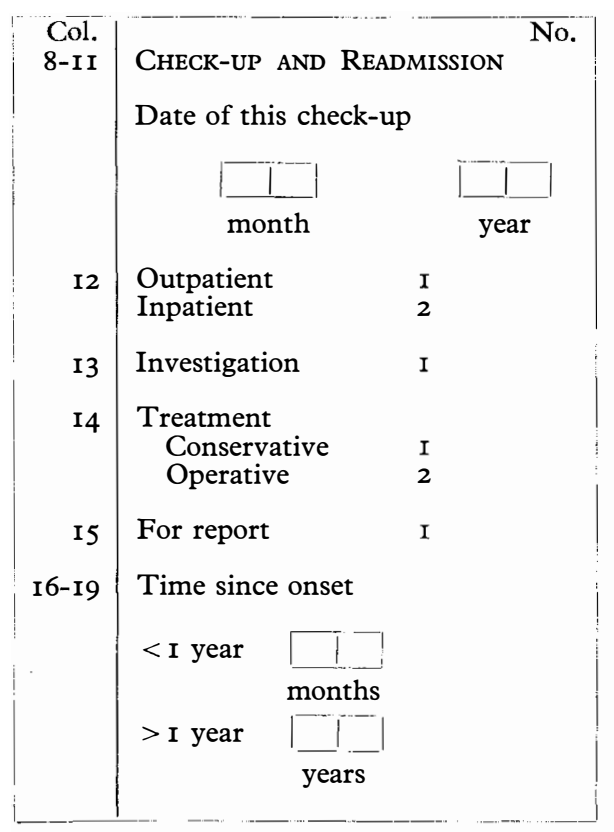

\begin{tabular}{|c|c|c|c|c|}
\hline 24 & $\begin{array}{l}\text { UROLOGICAL } \\
\text { Urine sterile } \\
\text { Urine infected } \\
\text { Result inconclusive }\end{array}$ & $\begin{array}{l}\text { I } \\
2 \\
3\end{array}$ & & \\
\hline 25 & Flare Up & I & & \\
\hline 26 & Orchitis & I & & \\
\hline 27 & Other & I & & \\
\hline 28 & Cytology & I & & \\
\hline 29 & \multicolumn{4}{|c|}{$\begin{array}{lr}\text { X-RAY URINARY } & \text { TRACT } \\
\text { Plain } & \text { I } \\
\text { TVP } & 2 \\
\text { Not Done } & 3\end{array}$} \\
\hline 30 & $\begin{array}{l}\text { RESULT } \\
\text { Stone not seen } \\
\text { Stone in kidney } \\
\text { Stone in ureter } \\
\text { Stone in bladder } \\
\text { Stone in prostate } \\
\text { Stone in more than } \\
\text { one site }\end{array}$ & $\begin{array}{l}\text { I } \\
2 \\
3 \\
4 \\
5 \\
6\end{array}$ & & \\
\hline $3 I-33$ & $\begin{array}{l}\text { IVP RESULT } \\
\text { No secretion } \\
\text { Poor } \\
\text { Normal } \\
\text { Hydronephrosis } \\
\quad \text { pelvis } \\
\text { calyces } \\
\text { cannonball } \\
\text { Ureteric changes }\end{array}$ & $\begin{array}{l}3 \text { I } \\
\text { I } \\
2 \\
3 \\
\\
4 \\
5 \\
6 \\
7\end{array}$ & $\begin{array}{l}32 \\
1 \\
2 \\
3\end{array}$ & $\begin{array}{l}33 \\
1 \\
2 \\
3\end{array}$ \\
\hline
\end{tabular}

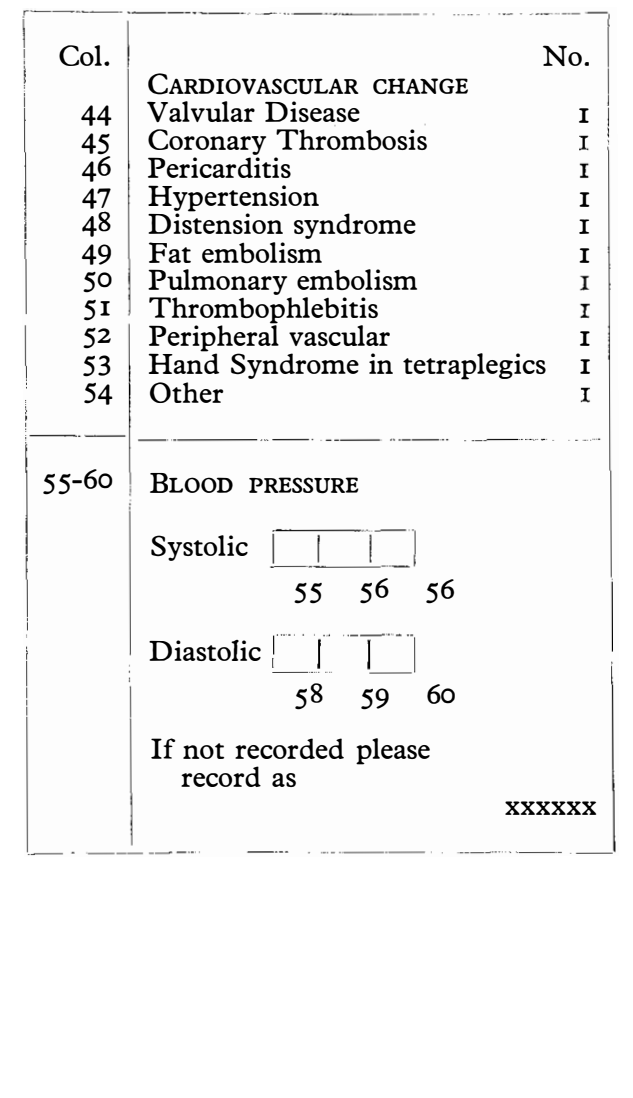

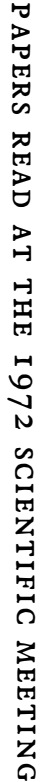

Fig. 2

Parts of check-up form relevant to this study. This information is used in conjunction with that in Figure I. 
DISTRIBUTION OF THE LEVEL OF SPINAL CORD LESION IN 540 PATIENTS
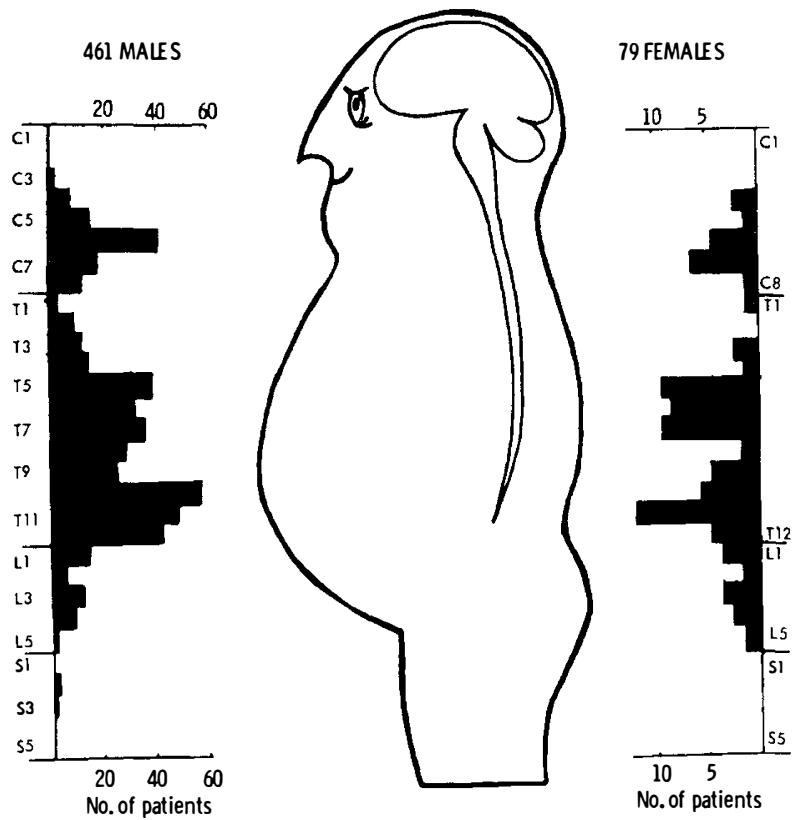

FIG. 3

MEAN SYSTOLIC BLOOD PRESSURE/LEVEL OF SPINAL CORD LESION

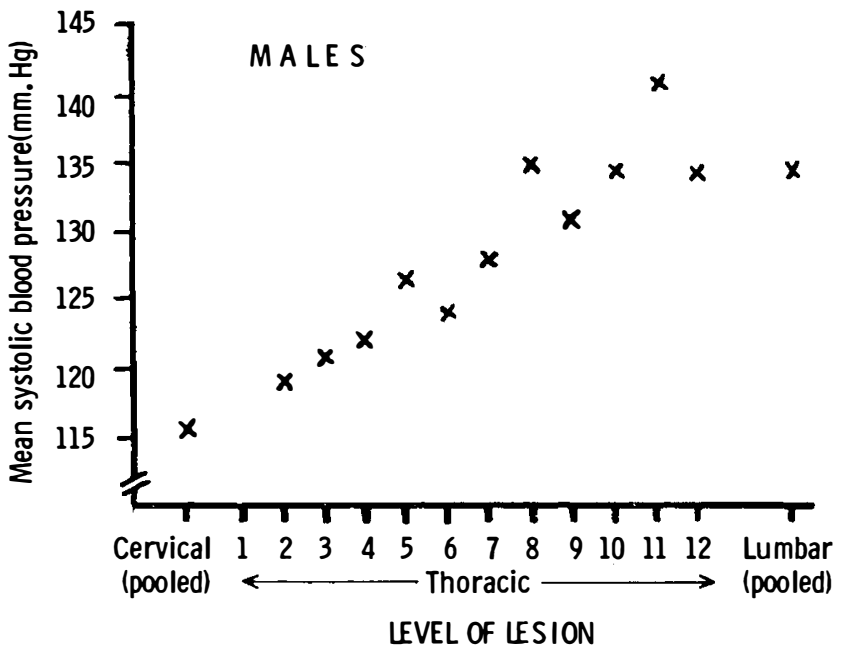

FIG. 4 
linear relationship within the cervical group). The lumbar lesions were also pooled.

This graph (fig. 4) shows a linear relationship; there is an increasing mean systolic B.P. as the level of the lesion progresses down the thoracic spinal cord. (The gradient of the regression line is $\mathrm{I} \cdot 97$, i.e. the mean systolic B.P. increases by I.97 $\mathrm{mm}$. Hg per segment-downwards-of the lesion.) The correlation coefficient (how near a straight line the points are) is $0.92 \mathrm{I}$.

MEAN DIASTOLIC BLOOD PRESSURE/LEVEL OF SPINAL CORD LESION

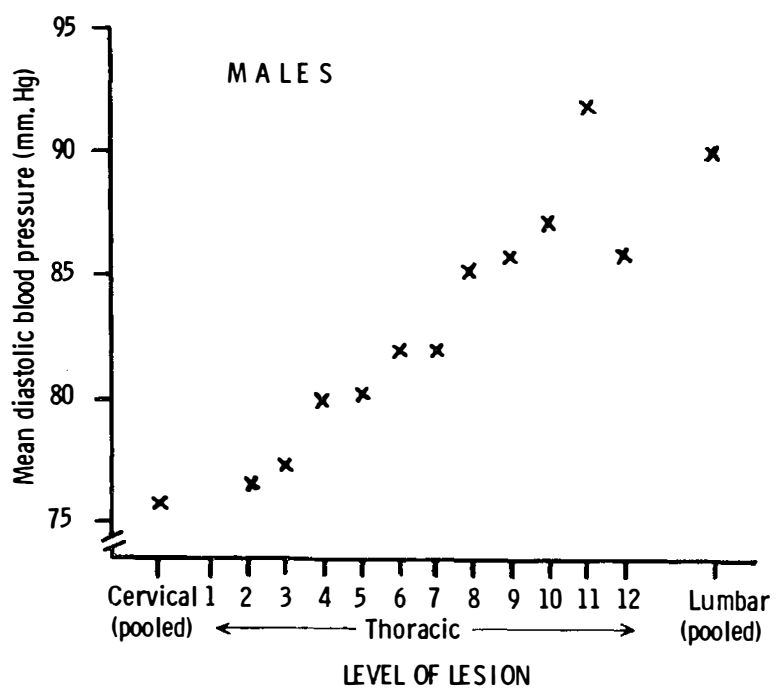

FIG. 5

Figure 5 shows the mean diastolic B.P. plotted in the same way as in Figure 4. Again, the linear relationship is shown, but in this case the gradient of the regression line is $I .25$ and the correlation coefficient 0.922 .

\section{DISCUSSION}

The main finding of the investigation was the linear relationship. If the results had been analysed by the previous method, (TI-T5, T6-TI2 and lumbar) a progressive rise in resting B.P. would have been shown but the striking linear relationship would have been missed.

Presented here are the results of a crude analysis and as, at this stage, no account has been taken of the patients' ages it is possible that when this is done the linear relationship may be slightly disturbed. In order to confirm these results it is intended to correlate all B.P.s with the patients' ages. This can be done with the present system, as the patients' year of birth, injury and check-up are all recorded on a punch card. It will also be possible to relate any B.P. falling outside the normal range for any particular neurological lesion to the presence or absence of urinary infection and renal complications.

This was a first attempt at using the information stored in the I.B.M. II30 
system. When more experience of this system is gained many more questions should be able to be answered.

\section{SUMMARY}

The resting B.P.s of patients with complete paraplegia and tetraplegia are recorded at their first check-up. The results are plotted for all the cervicals, each thoracic level and all the lumbar lesions. There is a progressive rise in systolic blood pressure from the cervical down to the lumbar lesions, with a striking linear relationship. The gradient of the regression line is $\mathrm{I} \cdot 97$ and the correlation coefficient is $0.92 \mathrm{I}$. The diastolic blood pressure shows a similar linear relationship. The gradient of the regression line is $I \cdot 25$ and the correlation coefficient is 0.922 .

\section{REFERENCES}

Talbot, H. S. (1966). Med. Serv. F. Canada, 22, 570.

TRIBE, C. R. (1963). Int. F. Paraplegia, I, I9.

Tribe, C. R. \& Silver, J. R. (I969). Renal Failure in Paraplegia. London: Pitman. 